\title{
Correlation of Wells Score, Prothrombin Time, Activated Partial Thromboplastin Time, Fibrinogen and D-Dimer Levels with Doppler Ultrasonography in Suspected Deep Vein Thrombosis Patients
}

\author{
Erny Alasiry ${ }^{1}$, Andi Fachruddin Benyamin ${ }^{2}$, Sahyuddin Saleh $^{2}$, Syakib Bakri ${ }^{1}$, Muhammad Ilyas ${ }^{1}$, Hasyim Kasim $^{1}$, \\ Idar Mapangara $^{1} \&$ Arifin Seweng ${ }^{3}$ \\ ${ }^{1}$ Department of Internal Medicine, Hasanuddin University’s Faculty of Medicine, South Sulawesi, Indonesia \\ ${ }^{2}$ Division of Hematology-Medical Oncology, South Sulawesi, Indonesia \\ ${ }^{3}$ Department of Biostatistics, Hasanuddin University's Faculty of Public Health, South Sulawesi, Indonesia \\ Correspondence: Erny Alasiry, Department of Internal Medicine, Hasanuddin University’s Faculty of Medicine, \\ Perintis Kemerdekaan Km 10, Tamalanrea, Makassar, South Sulawesi, Indonesia.
}

Received: May 13, 2020 Accepted: August 12, 2020 Online Published: September 4, 2020

doi:10.5539/gjhs.v12n11p1 URL: https://doi.org/10.5539/gjhs.v12n11p1

\begin{abstract}
Background/Aim: Venous thromboembolism (VTE) occur from formation of blood clots in the veins, which are mostly composed of fibrin and red blood cells with a small component of leukocytes and platelets. Most VTE manifests as deep vein thrombosis (DVT) and pulmonary embolism (PE). The lack of availability of Doppler ultrasound in health facilities especially in remote areas, makes the diagnosis of DVT challenging. There for, history taking, physical examination and laboratory findings are very important in diagnosing DVT especially in those area where Doppler ultrasound unavailable. Based on this we study the correlation Wells scores, Prothrombin Time (PT), Activated Partial Thromboplastin Time (APTT), Fibrinogen, and D-Dimer levels with the findings on Doppler ultrasound in patients with suspected DVT in Wahidin Sudirohusodo Hospital Makassar.
\end{abstract}

Method: The study was conducted in Department of Internal Medicine, Wahidin Sudirohusodo Hospital Makassar from 2018 to 2019. Subjects were inpatients in Department of Internal Medicine with DVT suspicion. Wells scores, PT, APTT, Fibrinogen, D-Dimer levels and Doppler ultrasound results of all subjects were recorded and then analyzed. The patient is DVT positive if confirmed by Doppler Ultrasonography. Statistical analysis was performed by descriptive statistical calculations and frequency distribution as well as the Independent-t statistical test, Chi Square test and Fisher Exact test.

Results: Among 38 subject, 24 were men (63.2\%) and 14 were women (36.8\%). We found higher Wells score, shortened PT and APTT, increased fibrinogen in subject with positive Doppler ultrasound, without a significant correlation. A significant correlation was found between increased D-Dimer levels positive Doppler ultrasound results $(79.4 \%, \mathrm{p}=0.048)$. When Wells score is added with analysis a significant correlation was also found $(80.6 \%, \mathrm{p}=0.044)$.

Conclusion: A significant correlation was found between increased D-Dimer levels positive Doppler ultrasound results $(79.4 \%, p=0.048)$. When Wells score is added with analysis a significant correlation was also found $(80.6 \%, \mathrm{p}=0.044)$.

Keywords: wells score, activated partial thromboplastin time, d-dimer, fibrinogen, prothrombin time, deep vein thrombosis

\section{Introduction}

Venous thromboembolism (VTE) occur from formation of blood clots in the veins, which are mostly composed of fibrin and red blood cells with a small component of leukocytes and platelets. Most VTE manifests as deep vein thrombosis (DVT) and pulmonary embolism (PE) (Kaushansky et al., 2010; Lopez et al., 2004)

Venous thrombosis, including DVT and PE, occurs at an annual incidence of about one per 1000 adults. About two-thirds of episodes manifest as DVT and one-thirds as PE with or without DVT (Cushman, 2007). Several studies also found that the incidence of DVT increases with age, occurs for the first time in about 100 persons per 100,000 each year in the United States, and rises exponentially from under five case per 100,000 persons under 15 
years old to about 500 cases $(0.5 \%)$ per 100.000 persons at age 80 years (Richard et al., 2003). Rates increase sharply after around age 45 years, and are slightly higher in men than women in older age (Cushman, 2007).

The occurrence of DVT is the final consecuences of imbalance between thrombogenic stimuli known as Virchov Triad (blood hypercoagulability, endothelial injury, and stasis or turbulence of blood flow) and protective factors (active coagulation factor inhibitors, elimination of active coagulation factors and fibrin polymer complexes by phagocytes mononuclear in the liver, as well as the enzyme fibrinolysis) (Kesieme et al., 2011). This condition is worsen by risk factors (age, surgery, pregnancy, trauma, malignancy, immobility, etc.) (Cushman, 2007; Kesieme et al., 2011).

A commonly accepted evidence based approach to diagnosis of DVT is the use of a clinical model that standardizes the clinical assesment (combining risk factors, signs, and symptoms) and subsequently stratifies patients suspected of DVT (Kesieme et al., 2011; Oudega et al., 2005). History and clinical examination are not reliable ways of diagnosing DVT. Lower extremity DVT can be symptomatic or asymptomatic. Patients with lower extremity DVT often do not present with erythema, pain, warmth, swelling, or tenderness. Symptomatic patients with proximal DVT may present with lower extremity pain, calf tenderness, and lower extremity swelling (Tapson et al., 1999; Kahn, 1998)

Patients with suspicion of DVT can be assessed by how likely is (clinical probability) towards the diagnosis using scoring system. Currently Wells score, Caprini score, Padua score and Khorana score can be used to diagnose but the most commonly used is Wells score due to its higher sensitivity, specificity and accuracy. Several point assessed in Wells score are whether the patient was diagnosed with active cancer (patients receiving treatment for cancer within the previous 6 months or currently receiving palliative treatment), has paralysis, paresis, or recent immobilization of the lower extremities, recently bedridden for three or more days or major surgery within the previous 12 weeks requiring general or regional anesthesia, localized tenderness along the distribution of the deep venous system, entire leg swollen, calf swelling at least three $\mathrm{cm}$ larger than asymptomatic side (measured $10 \mathrm{~cm}$ below the tibial tuberosity), pitting edema confined to the symptomatic leg, collateral superficial veins (nonvaricose), previously documented DVT, alternative diagnosis at least as likely as DVT (Baker's cyst, cellulitis, muscle damage, superficial venous thrombosis, post phlebitic syndrome, inguinal lymphadenopathy, external venous compression). Scores are obtained by adding up points for each positive item. Wells Score grades patient at low risk (score $\leq$ ), moderate risk (1-2), or high risk ( $\geq 3)$ for DVT (Dairion, 2016).

Due to imbalance of coagulation and fibrinolysis in DVT, conventional hemostasis tests such as Prothrombin Time (PT), Activated Partial Thromboplastin Time (APTT), and Fibrinogen levels, were routinely performed to determine coagulation activation, whereas D-Dimer is perform to determine fibrinolysis activation (Setiabudy, 2012). Hypercoagulable state is indicated when coagulation system is active, which will result in shortened PT and APTT, increased Fibrinogen, D-Dimers and platelet count (Zakai et al., 2008).

However, in the diagnosis of DVT, angiography (venography or phlebography) remains to be the gold standard. Under certain conditions the role of angiography can be replaced with non-invasive ultrasound examination (Doppler ultrasound) (Setiabudy, 2012).

The lack of availability of Doppler ultrasound in health facilities especially in remote areas, makes the diagnosis of DVT challenging. Therefore, history taking, physical examination and laboratory findings are very important in diagnosing DVT especially in those area where Doppler ultrasound unavailable.

Based on this we study the correlation Wells scores, PT, APTT, Fibrinogen, D-Dimer levels with the findings on Doppler ultrasound in patients with suspected DVT in Wahidin Sudirohusodo Hospital Makassar.

\section{Method}

\subsection{Sampling Procedures}

The study was conducted in the Department of Internal Medicine, Wahidin Sudirohusodo Hospital Makassar from 2018 to 2019. The research subjects were DVT suspected patients who were hospitalized in the Department of Internal Medicine, Wahidin Sudirohusodo Hospital Makassar.

\subsection{Inclusion and Exclusion Criteria}

Inclusion criteria were hospitalized patients, age $\geq 40$ years who were suspected with DVT. Suspicion of DVT can be assessed based on history taking, physical examination and the presence of risk factors. Clinical probability of DVT in a patient can be predicted using certain scoring method. In this study we use Wells scoring system. Exclusion criteria were surgery planned patients, pregnancy, already receiving antithrombotic drugs, the presence of liver disorders and thrombocytopenia. 


\subsection{Statistical Analysis}

The study was observational study with a retrospective cohort study design, by analyzing correlation between Wells scores, PT, APTT, Fibrinogen and D-Dimer levels with Doppler ultrasound in patients with suspected DVT. Data analysis was performed using SPSS version 22. Statistical analysis was performed by using descriptive statistical calculations and frequency distribution as well as the Independent-t statistical test, Chi Square test and Fisher Exact test. The test results are significant if the $\mathrm{p}$ value $<0.05$.

\section{Results}

\subsection{Characteristics Research Subjects}

Among 38 subjects, 24 (63.2\%) were male and 14 (36.8\%) were female. There were no significant differences in sex in patients with suspected DVT. Subjects aged $\leq 50$ years were $8(21.1 \%)$ and aged $>50$ years were $30(78.9 \%)$, with an average age of $56.2 \pm 9.2$. Doppler ultrasound were positive in $28(73.7 \%)$ subjects and negative in 10 $(26.3 \%)$ subjects as seen in Table 1.

Table 1. Characteristics of Research Subjects Based on Amount and Percentage

\begin{tabular}{llll}
\hline Variable & & $\mathbf{n}$ & $\mathbf{\%}$ \\
\hline \multirow{2}{*}{ Gender } & Male & 24 & 63,2 \\
& Female & 14 & 36,8 \\
\hline \multirow{2}{*}{ Age } & $\leq 50$ years & 8 & 21,1 \\
& $>50$ years & 30 & 78,9 \\
\hline \multirow{2}{*}{ USG Doppler } & Positive & 28 & 73,7 \\
& Negative & 10 & 26,3 \\
\hline
\end{tabular}

3.2 Correlation between Wells Score, PT, APTT, Fibrinogen, and D-Dimer with Doppler Ultrasound Results in Patients with Suspected DVT

We found higher Wells score, shortened PT and APTT, increased fibrinogen in subject with positive Doppler ultrasound, without a significant correlation. A significant correlation was found between increased D-Dimer level and positive Doppler ultrasound $(79.4 \%, \mathrm{p}=0.048)$ as shown in Table 2 . When Wells score is added to the analysis a significant correlation was also found $(80.6 \%, \mathrm{p}=0.044)$.

Table 2. Correlation between Wells Score, PT, APTT, Fibrinogen, and D-Dimer with Doppler ultrasound results in patients with suspected DVT

\begin{tabular}{|c|c|c|c|c|c|c|}
\hline & & & \multicolumn{2}{|c|}{ Doppler USG } & \multirow{2}{*}{ Total } & \multirow{2}{*}{$\mathbf{p}$} \\
\hline & & & Positive & Negative & & \\
\hline \multirow{4}{*}{ Wells Score } & \multirow{2}{*}{ Moderate Risk } & $\mathrm{n}$ & 2 & 1 & 3 & \multirow{4}{*}{0,612} \\
\hline & & $\%$ & $66,7 \%$ & $33,3 \%$ & $100,0 \%$ & \\
\hline & \multirow{2}{*}{ High Risk } & $\mathrm{n}$ & 26 & 9 & 35 & \\
\hline & & $\%$ & $74,3 \%$ & $25,7 \%$ & $100,0 \%$ & \\
\hline \multirow{4}{*}{ PT } & \multirow{2}{*}{ Shorten } & $\mathrm{n}$ & 1 & 0 & 1 & \multirow{4}{*}{0,737} \\
\hline & & $\%$ & $100,0 \%$ & $0,0 \%$ & $100,0 \%$ & \\
\hline & \multirow{2}{*}{ Normal } & $\mathrm{n}$ & 27 & 10 & 37 & \\
\hline & & $\%$ & $73,0 \%$ & $27,0 \%$ & $100,0 \%$ & \\
\hline \multirow{4}{*}{ APTT } & \multirow{2}{*}{ Shorten } & $\mathrm{n}$ & 1 & 0 & 1 & \multirow{4}{*}{0,737} \\
\hline & & $\%$ & $100,0 \%$ & $0,0 \%$ & $100,0 \%$ & \\
\hline & \multirow{2}{*}{ Normal } & $\mathrm{n}$ & 27 & 10 & 37 & \\
\hline & & $\%$ & $73,0 \%$ & $27,0 \%$ & $100,0 \%$ & \\
\hline
\end{tabular}




\begin{tabular}{|c|c|c|c|c|c|c|}
\hline \multirow{4}{*}{ Fibrinogen } & \multirow{2}{*}{ Increased } & $\mathrm{n}$ & 14 & 2 & 16 & \multirow{4}{*}{0,089} \\
\hline & & $\%$ & $87,5 \%$ & $12,5 \%$ & $100,0 \%$ & \\
\hline & \multirow{2}{*}{ Normal } & $\mathrm{n}$ & 14 & 8 & 22 & \\
\hline & & $\%$ & $63,6 \%$ & $36,4 \%$ & $100,0 \%$ & \\
\hline \multirow{4}{*}{ D-Dimer } & \multirow{2}{*}{ Increased } & $\mathrm{n}$ & 27 & 7 & 34 & \multirow{4}{*}{0,048} \\
\hline & & $\%$ & $79,4 \%$ & $20,6 \%$ & $100,0 \%$ & \\
\hline & \multirow{2}{*}{ Normal } & $\mathrm{n}$ & 1 & 3 & 4 & \\
\hline & & $\%$ & $25,0 \%$ & $75,0 \%$ & $100,0 \%$ & \\
\hline
\end{tabular}

\subsection{Correlation between Wells Scores with D-Dimer Levels in Patients with Suspected DVT}

We also analize the correlation of Wells score with D-Dimer in patient with suspected DVT. Among all subjects in each Wells score risk group shown increased D-Dimer, but with no significant correlation $(p$ value $=0.709)$ as shown in Table 3.

Table 3. Correlation between Wells scores with D-Dimer levels in patients with suspected DVT

\begin{tabular}{|c|c|c|c|c|c|}
\hline \multirow{2}{*}{ Wells scores } & & \multicolumn{2}{|l|}{ D-Dimer } & \multirow{2}{*}{ Total } & \multirow{2}{*}{$\mathbf{p}$} \\
\hline & & Increased & Normal & & \\
\hline \multirow{2}{*}{ Moderate Risk } & $\mathrm{n}$ & 3 & 0 & 3 & \multirow{6}{*}{0,709} \\
\hline & $\%$ & $100,0 \%$ & $0,0 \%$ & $100,0 \%$ & \\
\hline \multirow{2}{*}{ High Risk } & $\mathrm{n}$ & 31 & 4 & 35 & \\
\hline & $\%$ & $88,6 \%$ & $11,4 \%$ & $100,0 \%$ & \\
\hline \multirow{2}{*}{ Total } & $\mathrm{n}$ & 34 & 4 & 38 & \\
\hline & $\%$ & $89,5 \%$ & $10,5 \%$ & $100,0 \%$ & \\
\hline
\end{tabular}

3.4 Correlation between Wells Scores, D-Dimer Levels and Doppler Ultrasound Results in Patients with Suspected $D V T$

We then further analyze the correlation of Wells scores, D-Dimer levels and Doppler ultrasound results in patients with suspected DVT. We found a significant correlation between positive Doppler findings, high risk Wells score and increased D-Dimer ( $\mathrm{p}$ value $=0.044$ ) as shown in Table 4 .

Table 4. Correlation between Wells scores, D-Dimer levels and Doppler ultrasound results in patients with suspected DVT

\begin{tabular}{|c|c|c|c|c|c|c|c|}
\hline \multirow{2}{*}{ Wells scores } & \multirow{2}{*}{ D-Dimer } & & \multicolumn{3}{|c|}{ USG Doppler } & \multirow{2}{*}{ Total } & \multirow{2}{*}{$\mathbf{p}$} \\
\hline & & & Positive & & Negative & & \\
\hline \multirow{4}{*}{ Moderate Risk } & \multirow{2}{*}{ Increased } & $\mathrm{n}$ & 2 & 1 & 3 & & \multirow{4}{*}{$\mathrm{p}=$ undetermined } \\
\hline & & $\%$ & $66,7 \%$ & $33,3 \%$ & 1 & & \\
\hline & \multirow{2}{*}{ Total } & $\mathrm{n}$ & 2 & & 1 & 3 & \\
\hline & & $\%$ & $66,7 \%$ & & $33,3 \%$ & $100,0 \%$ & \\
\hline \multirow{6}{*}{ High Risk } & \multirow{2}{*}{ Increased } & $\mathrm{n}$ & 25 & & 6 & 31 & \multirow{6}{*}{$\mathrm{p}=0,044$} \\
\hline & & $\%$ & $80,6 \%$ & & $19,4 \%$ & $100,0 \%$ & \\
\hline & \multirow{2}{*}{ Normal } & $\mathrm{n}$ & 1 & & 3 & 4 & \\
\hline & & $\%$ & $25,0 \%$ & & $75,0 \%$ & $100,0 \%$ & \\
\hline & \multirow{2}{*}{ Total } & $\mathrm{n}$ & 26 & & 9 & 35 & \\
\hline & & $\%$ & $74,3 \%$ & & $25,7 \%$ & $100,0 \%$ & \\
\hline
\end{tabular}




\section{Discussion}

Suspicion of DVT can be assessed based on history taking, physical examination and the presence of risk factors. Clinical probability of DVT in a patient can be predicted using certain scoring method. In this study we use Wells score system due to its higher sensitivity, specificity and accuracy (Dairion, 2016).

In this study we found that PT and APTT were mostly normal in subjects with suspicion of DVT, nevertheless we found that all subjects with shortened PT and APTT, gave positive findings in Doppler ultrasound (Table 2). In DVT, extrinsic and intrinsic pathway coagulation were activated, resulting shortened PT and APTT in hypercoagulable phase (Zakai et al., 2008).

A retrospective study by Song et al., PT and APTT were shortened in experimental animals with hypercoagulability, increasing the incidence of thrombosis, possibility of PE, and circulation D-Dimer (Song et al., 2016). Activation of coagulation will cause overall formation of fibrin in circulation. Excess consumption of coagulation factors and platelets, result in decompensation where PT and APTT can become normal or prolonged, which caused by the activation of coagulation, so that the coagulation factors from extrinsic and intrinsic pathways decreased causing the PT and APTT to become normal or prolonged. Normal or prolonged PT and APTT can also caused by the late activation of coagulation, as a results from compensation through increased production of coagulation factors by the liver (Mammen, 1998; Yu et al., 2000; Korte et al., 2000). This condition is the reason why we found more normal PT and APTT in the subject.

This study also found normal Fibrinogen levels in most patients with suspicion of DVT. Fibrinogen levels in DVT should increase due to the nature of Fibrinogen as an acute phase reactant released during thrombosis and remain high in the longer periode. This finding was also validated in a rodent model, where intravenous infusion of Fibrinogen in mice resulted in a shorter time to vessel occlusion and a larger thrombus (Machlus et al., 2011). Fibrinogen levels can be found normal in patients with DVT due to its increased production in condition where the need for Fibrinogen was also increased (Mammen, 1998; Yu et al., 2000; Machlus et al., 2011).

Patients with high Wells scores have a high clinical probability for DVT (Dairion, 2016; Ginsberg et al., 1997). D-Dimer levels increase in various number of conditions that trigger fibrin production and catabolizm including DVT. In this study we found that D-Dimer levels increased in most patients with suspicion of DVT because in DVT coagulation activation will immediately be followed by activation of fibrinolysis. In fibrinolysis, cross-linked fibrin will be broken down by plasmin to produce D-Dimers resulting in increasing level of D-Dimer in circulation (Ginsberg et al., 1997; Wells, 2003). In this study we also found a correlation between increased D-Dimer levels and high Wells scores in patients with suspected DVT This is similar to Ginsberg's study evaluating the D-Dimer examination in 398 patients with suspected DVT using the Wells score criteria. In patients with a low risk group, only one of 178 patients with negative D-Dimer results had DVT. Overall negative predictive value from this examination was $97.2 \%$ (Ginsberg et al., 1997).

\section{Conclusion}

A significant correlation was found between increased D-Dimer levels positive Doppler ultrasound results (79.4\%, $\mathrm{p}=0.048)$. When Wells score is added with analysis a significant correlation was also found $(80.6 \%, \mathrm{p}=0.044)$.

\section{Source of Funding}

This study was conducted with self funding, no external funding sources for this study

\section{Ethical Clearance}

The study protocol was approved by the Health Research Ethics Comission (Faculty of Medicine Hasanuddin University), following the ethical reccomendations from the Helsinki Declaration of 1975.

\section{Competing Interests Statement}

No Potential conflict of interest relevant to be declared.

\section{References}

Cushman, M. (2007). Epidemiology and Risk Factors for Venous Thrombosis. Semin Hematol, 44(2), 62-69. https://doi.org/10.1053/j.seminhematol.2007.02.004

Gatot, D. (2016). Perbedaan Akurasi Skor Wells Dengan Skor Padua Dalam Diagnosis Deep Vein Trombosis (Master's thesis). Universitas Sumatera Utara, Medan, 1-27.

Ginsberg, J. S., Kearon, C., Douketis, J., Turpie, A. G., Brill-Edwards, P., Stevens, P., ... \& Massicotte, M. P. (1997). The use of D-dimer testing and impedance plethysmographic examination in patients with clinical 
indications of deep vein thrombosis. Archives of Internal Medicine, 157(10), 1077-1081. https://doi.org/10.1001/archinte.1997.00440310041004

Kahn, S. R. (1998). The clinical diagnosis of deep venous thrombosis: integrating incidence, risk factors, and symptoms and signs. Archives of internal medicine, 158(21), 2315-2323. https://doi.org/10.1001/archinte.158.21.2315

Kesieme, E., Kesieme, C., Jebbin, N., Irekpita, E., \& Dongo, A. (2011). Deep vein thrombosis: a clinical review. Journal of blood medicine, 2, 59. https://doi.org/10.2147/JBM.S19009

Korte, W., Clarke, S., \& Lefkowitz, J. B. (2000). Short activated partial thromboplastin times are related to increased thrombin generation and an increased risk for thromboembolism. American journal of clinical pathology, 113(1), 123-127. https://doi.org/10.1309/G98J-ANA9-RMNC-XLYU

Lopez, J. A., Kearon, C., \& Lee, A. Y. Y. (2004). Deep venous thrombosis. Hematology Am Soc Hematol Educ Program, 32(1), 439-456. https://doi.org/10.1182/asheducation-2004.1.439

Machlus, K. R., Cardenas, J. C., Church, F. C., \& Wolberg, A. S. (2011). Causal relationship between hyperfibrinogenemia, thrombosis, and resistance to thrombolysis in mice. Blood, The Journal of the American Society of Hematology, 117(18), 4953-4963. https://doi.org/10.1182/blood-2010-11-316885

Mammen, E. F. (1998). The haematological manifestations of sepsis. The Journal of antimicrobial chemotherapy, 41(suppl_1), 17-24. https://doi.org/10.1093/jac/41.suppl_1.17

Oudega, R., Moons, K. G., \& Hoes, A. W. (2005). Limited value of patient history and physical examination in diagnosing deep vein thrombosis in primary care. Family practice, 22(1), 86-91. https://doi.org/10.1093/fampra/cmh718

Rahajuningsih, D. S. (2018). Hemostasis dan trombosis.

Raskob, G. E., Hull, D. R., \& Buller. (2010). Venous Thrombosis (9e(133), 2700-2720). Williams Hematology, McGraw-Hill Companies Inc.

Richard, H., \& White, M. D. (2003). The Epidemiology of Venous Thromboembolism. Circulatio, 107, I-4 - I-8. https://doi.org/10.1161/01.CIR.0000078468.11849.66

Song, J., Drobatz, K. J., \& Silverstein, D. C. (2016). Retrospective evaluation of shortened prothrombin time or activated partial thromboplastin time for the diagnosis of hypercoagulability in dogs: 25 cases (2006-2011). Journal of Veterinary Emergency and Critical Care, 26(3), 398-405. https://doi.org/10.1111/vec.12478

Tapson, V. F., Carroll, B. A., Davidson, B. L., Elliott, C. G., Fedullo, P. F., Hales, C. A., ... \& Moser, K. M. (1999). The diagnostic approach to acute venous thromboembolism. Clinical practice guideline. American Thoracic Society. American journal of respiratory and critical care medicine, 160(3), 1043. https://doi.org/10.1164/ajrccm.160.3.16030

Wells, P. S., Anderson, D. R., Rodger, M., Forgie, M., Kearon, C., Dreyer, J., ... \& Kovacs, M. J. (2003). Evaluation of D-dimer in the diagnosis of suspected deep-vein thrombosis. New England Journal of Medicine, 349(13), 1227-1235. https://doi.org/10.1056/NEJMoa023153

Yu, M., Nardella, A., \& Pechet, L. (2000). Screening tests of disseminated intravascular coagulation: guidelines for rapid and specific laboratory diagnosis. Critical care medicine, 28(6), 1777-1780.https://doi.org/10.1097/00003246-200006000-00013

Zakai, N. A., Ohira, T., White, R., Folsom, A. R., \& Cushman, M. (2008). Activated partial thromboplastin time and risk of future venous thromboembolism. The American journal of medicine, 121(3), 231-238. https://doi.org/10.1016/j.amjmed.2007.10.025

\section{Copyrights}

Copyright for this article is retained by the author(s), with first publication rights granted to the journal.

This is an open-access article distributed under the terms and conditions of the Creative Commons Attribution license (http://creativecommons.org/licenses/by/4.0/). 